\title{
Relationship between Energy Consumption and Speed of the EMU
}

\author{
Hai-Bo ZHAO \\ CRRC Changchun Railway Vehicles Co., Ltd, Changchun,130000,China \\ email: zhaohaibo@cccar.com.cn
}

Keywords: EUM energy; operation consumption; operation time; EMU

\begin{abstract}
This paper analyzed the relationship between the application of EMU and energy consumption ; on the basis of introducing the EMU at home and abroad in detail in this paper, the analysis were done from traction fields and the comparisons of relationship between operation mileage of the EMU , time, speed, and energy consumption were finished . The optimal matching between the application of EMU and the energy consumption relation was obtained.
\end{abstract}

\section{Introduction}

In recent years the rapid development of the railway passenger transportation in our country, the demands for high speed passenger transportation cars and transportation facilities are increasing . In order to adapt to the development of market economy, meet the demand of labor force and population flow and keep the railway passenger transportation in the dominant position in the carriage of passengers, chosing high speed, safe, energy -saving, comfortable railway passenger transportation EMU is necessary. Reasonable selection of the EMU has important significance to save energy, improve the efficiency of transportation, relieve the strain on the car, reduce operating costs, improve equipment level of railway transportation and the social material civilization. Will also lead to the raw material (aluminum alloy) processing industry, electrical appliances and development of rail transportation and related industries, and become a new growth point of economy development. In order to reduce operation costs, the design of the foreign railway vehicles is designed to use their own special railways at present, this is not fit in with our national condition. On the base of analysing the EMU at home and abroad and from the Angle of energy, the optimal matching relationship between consumption of the EMU operation mileage and the operating time was analysed, thus achieved the purpose to reduce the energy consumption at the optimal speed and time[1][2].

\section{The main parameters and application situation of EMU}

1)EMUs in China are divided into diesel EMUs and distributed-power EMUs ,now the EMUS mainly refers to the power EMUS, now the running EMUs are:

2)CRH1, which operation speed is $200 \sim 250 \mathrm{~km} / \mathrm{h}$.

3)CRH2 , which operating is $200 \sim 300 \mathrm{~km} / \mathrm{h}$.

3)CRH3 , which operation speed is $300 \sim 330 \mathrm{~km} / \mathrm{h}$.

4)CRH5 , which operation spees is $200 \sim 250 \mathrm{~km} / \mathrm{h}$.

5)CRH380, which urrently operation speed is $300 \sim 350 \mathrm{~km} / \mathrm{h}$.

The train whose speed is 200 or $300 \mathrm{~km} / \mathrm{h}$ can run on the modified common railways, but when the speed reaches to300 km/h and higher, the EMUs must run on special strengthening high speed railway. 
Table 1. The main parameters of CRH

\begin{tabular}{|c|c|c|c|c|c|c|}
\hline Modle & CRH1 & CRH2 & CRH3 & CRH5 & CRH380BL & CRH380CL \\
\hline Group & $5 \mathrm{M} 3 \mathrm{~T}$ & $6 \mathrm{M} 2 \mathrm{~T}$ & $4 \mathrm{M} 4 \mathrm{~T}$ & $5 \mathrm{M} 3 \mathrm{~T}$ & $8 \mathrm{M} 8 \mathrm{~T}$ & $8 \mathrm{M} 8 \mathrm{~T}$ \\
\hline Length(m) & 200 & 200 & 200 & 200 & 400 & 400 \\
\hline $\begin{array}{c}\text { Vehicle weight } \\
\text { (t) }\end{array}$ & 470 & 440 & 490 & 493 & 1000 & 1000 \\
\hline $\begin{array}{c}\text { Capacity } \\
\text { (people) }\end{array}$ & 670 & 610 & 794 & 608 & 1050 & 1050 \\
\hline $\begin{array}{c}\text { Highest } \\
\text { speed(km/h) }\end{array}$ & 250 & 300 & 300 & 300 & 350 & 350 \\
\hline $\begin{array}{c}\text { Total power } \\
\text { (kw/column) }\end{array}$ & 5500 & 4800 & 8800 & 5500 & 18400 & 19200 \\
\hline
\end{tabular}

\section{The comparison of CRH traction characteristic}

Now choosing traction characteristics according to the characteristics of the traction motor, there are a few key points, namely, vehicle weight, start the traction, start acceleration, basic running resistance, constant power turning point, rated power, residual acceleration at high speed and so on, these are related to energy consumption. These are related to energy consumption. EMU traction characteristic curves under different speed levels are showned in figure 1.

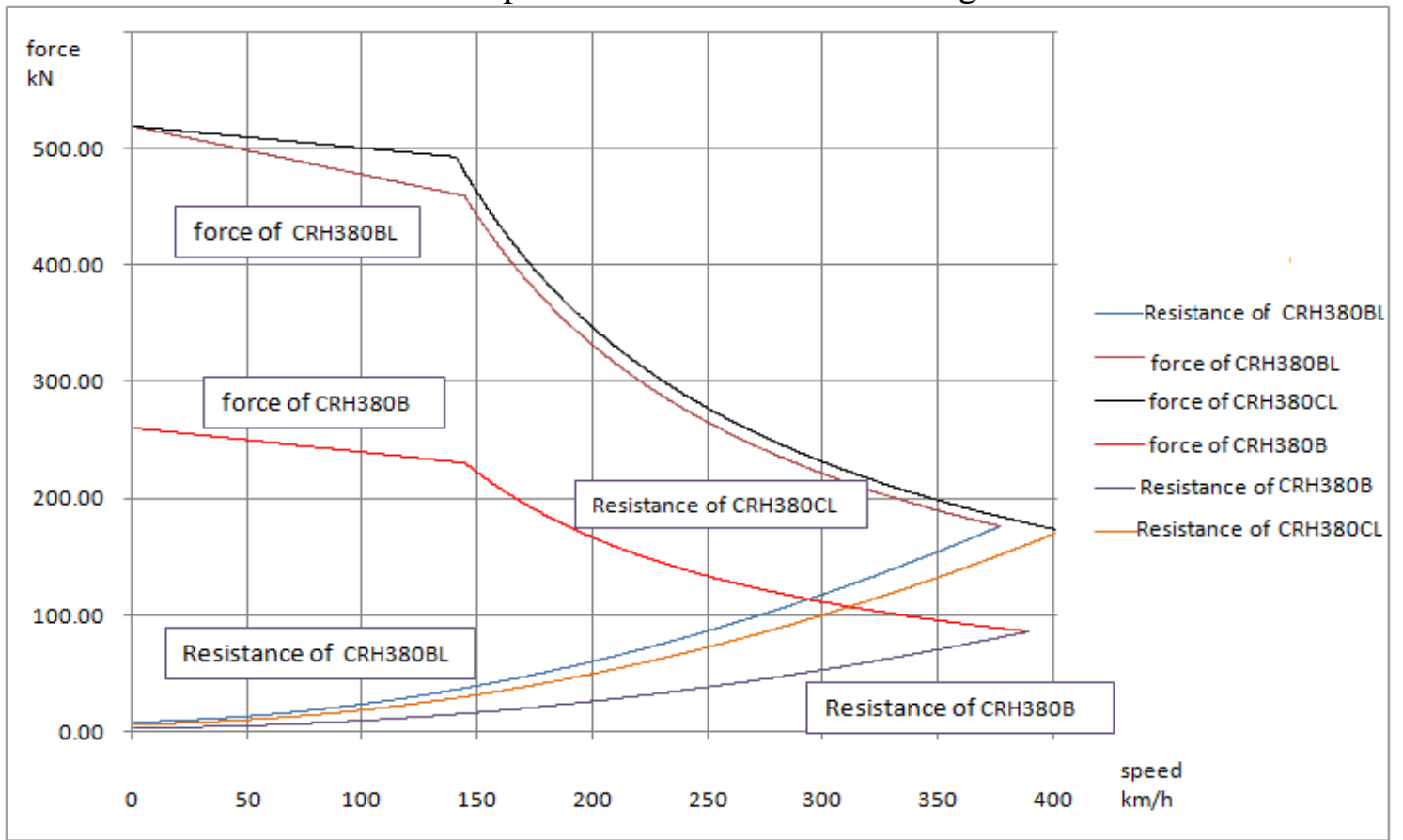

Figure 1. Traction characteristic curve of CHR

TABLE 2 TRACTION CHARACTERISTIC KEY PARAMETERS OF CHR

\begin{tabular}{|c|c|c|c|}
\hline Models & CRH380B & CRH380BL & CRH380CL \\
\hline marshalling weight (t) & 522 & 1037 & 1058.4 \\
\hline starting traction (kN) & 260 & 520 & 520 \\
\hline starting acceleration (m/s $\mathbf{s})$ & 0.49 & 0.49 & 0.49 \\
\hline basic running resistance & $\begin{array}{c}3699.5+36.73 * v \\
+6.65 * v^{2}\end{array}$ & $\begin{array}{c}7680.6+192.554^{*} v+1 \\
3.5^{*} v^{2}\end{array}$ & $5523.7+97.16^{*} v+12.45^{*} v^{2}$ \\
\hline $\begin{array}{l}\text { turning point of constant } \\
\text { power(km/h) }\end{array}$ & 144 & $144 \mathrm{k}$ & 140 \\
\hline total power $(\mathbf{k w / c o l u m n )}$ & 8800 & 18400 & 19200 \\
\hline residual acceleration(m/s $\mathbf{s})$ & 0.05 & 0.05 & 0.05 \\
\hline
\end{tabular}




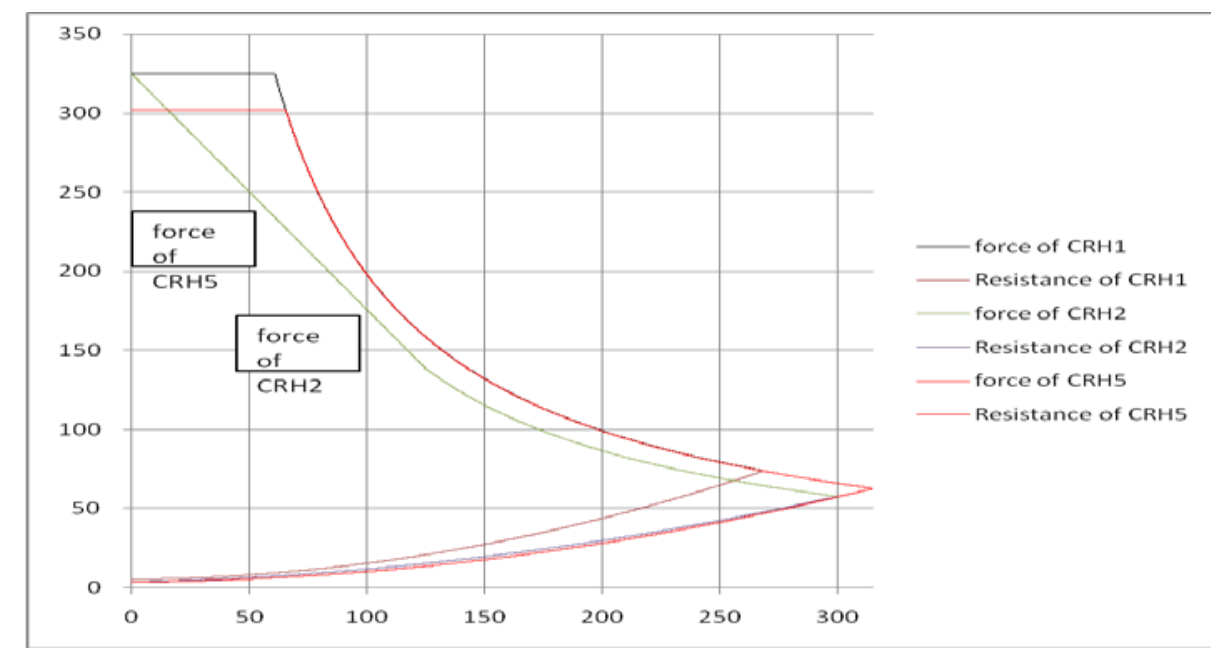

FIGURE 2. TRACTION CHARACTERISTIC CURVE OF $250 \mathrm{KM} / \mathrm{H}$ CHR

TABLE 3 TRACTION CHARACTERISTICS KEY PARAMETERS OF $250 \mathrm{KM} / \mathrm{H}$ HARMONY EMU

\begin{tabular}{|l|c|c|c|}
\hline Models & CRH1 & CRH2 & CRH5 \\
\hline marshalling weight (t) & 474 & 440 & 474 \\
\hline starting traction (kN) & 325 & 325 & 325 \\
\hline starting acceleration (m/s $\mathbf{s})$ & 0.6 & 0.6 & 0.6 \\
\hline basic running resistance & $5200+37.2^{*} v+11.877^{*} v^{2}$ & $3797.2+32.1^{*} v+0.49^{*} v^{2}$ & $5200+37.2^{*} v+11.877^{*} v^{2}$ \\
\hline $\begin{array}{l}\text { turning point of constant } \\
\text { power(km/h) }\end{array}$ & 61 & 125 & 65 \\
\hline total power $(\mathbf{k w / c o l u m n )}$ & 5500 & 4800 & 5500 \\
\hline residual acceleration(m/s $\mathbf{s})$ & 0.03 & 0.06 & 0.07 \\
\hline
\end{tabular}

\section{The relationship between energy operators and operating hours}

In the condition of traction, the power supply of EMU is AC $25 \mathrm{kV} 50 \mathrm{~Hz}$.In the condition of braking, it uses regenerative braking to feed back the energy to ac power grid[3][4].

The premises of the analysis are as follows: the EMU is on the straight line of 100 kilometers, starting-constant running at the highest speed-braking. In the whole operation process it does not take into account the driver control forms, gradient resistance, curve resistance and so on, during deceleration the maximum deceleration acceleration is $-1.0 \mathrm{~m} / \mathrm{s}^{2}$, ignore the parking of the air braking effect[4][5].

Table 4 Main characteristics key parameters of EMU

\begin{tabular}{|c|c|c|c|c|c|c|}
\hline & CRH1 & CRH2 & CRH5 & CRH380B & CRH380CL & \\
\hline design weight & 474 & 440 & 474 & 523 & 1058.4 & $\mathbf{t}$ \\
\hline tractive power & 5500 & 4800 & 5500 & 8800 & 19200 & $\mathbf{k W}$ \\
\hline maximum velocity & 250 & 250 & 250 & 350 & 350 & $\mathbf{k m} / \mathbf{h}$ \\
\hline $\begin{array}{c}\text { running } \\
\text { resistance(250km/h) }\end{array}$ & 65 & 42 & 41 & 70 & 133 & $\mathbf{k N}$ \\
\hline time(0 250km/h) & 404 & 342 & 315 & 487 & 440 & $\mathbf{s}$ \\
\hline distance(0 250km/h) & 21 & 17 & 15 & 33 & 29 & $\mathbf{k m}$ \\
\hline $\begin{array}{c}\text { tractive energy } \\
\text { consumption } \\
\mathbf{( 0 ~} \mathbf{2 5 0 k m / h )}\end{array}$ & 618 & 456 & 482 & 1245 & 2346 & $\mathbf{k W . h}$ \\
\hline $\begin{array}{c}\text { time(250km/h 0) } \\
\text { distance(250km/h 0) }\end{array}$ & 3.2 & 3.4 & 3 & 6 & 7 & $\mathbf{k m}$ \\
\hline $\begin{array}{c}\text { renewable } \\
\text { energy(250km/h 0) }\end{array}$ & $(116)$ & $(106)$ & $(123)$ & $(282)$ & $(611)$ & $\mathbf{k W . h}$ \\
\hline
\end{tabular}




\section{Conclusion}

Compare the above analysis shows that the same level of speed EMUs running time per one hundred kilometers is basically the same, but the energy consumption of different EMU (equivalent to 8 grouping) is different. Shown in table5:

Table 5 The energy consumption of different EMUs

\begin{tabular}{|c|c|c|c|c|c|c|}
\hline \multicolumn{2}{|c|}{} & CRH1 & CRH2 & CRH5 & CRH380B & CRH380CL \\
\hline \multirow{2}{*}{$\mathbf{1 0 0 K m}$} & Energy consumption (kw.h) & 1865 & 1222 & 1274 & 2126 & 2096 \\
\cline { 2 - 7 } & time(m) & 27 & 27 & 27 & 20 & 20 \\
\hline \multirow{2}{*}{$\mathbf{2 0 0 K m}$} & Energy consumption (kw.h) & 3694 & 2478 & 2412 & 41879 & 3834 \\
\cline { 2 - 7 } & time(min) & 51 & 51 & 51 & 36 & 36 \\
\hline \multirow{2}{*}{$\mathbf{5 0 0 K m}$} & energy consumption (kw.h) & 9054 & 6026 & 5967 & 9912 & 9387 \\
\cline { 2 - 7 } & time(min) & 121 & 121 & 11 & 94 & 92 \\
\hline \multirow{2}{*}{$\mathbf{1 0 0 0 K m}$} & energy consumption (kw.h) & 18234 & 17518 & 11679 & 19349 & 18418 \\
\cline { 2 - 7 } & time(min) & 236 & 239 & 241 & 172 & 172 \\
\hline
\end{tabular}

From the table above can get the following conclusion:

1)In the $250 \mathrm{~km} / \mathrm{h}$ level EMU, the energy consumption of CRH2 and CRH5 is basically the same. In the $350 \mathrm{~km} / \mathrm{h}$ level EMU, CRH380CL EMU consumes the least energy.

2) Different speed levels of EMU on the same line, $250 \mathrm{~km} / \mathrm{h}$ level EMU elapsed time is 26 minutes per hundred kilometers. It spent more than $350 \mathrm{~km} / \mathrm{h}$ EMU level five minutes. But the difference in energy consumption is very large, reaching $50 \%$ or higher.

3) The distance is about one hundred kilometers between two stations, such as the inter-city lines need a large volume of short circuits, suitable for locomotive speed of $250 \mathrm{~km} / \mathrm{h}$ speed level EMU. This speed level EMU have small impact on the line. The costs of line maintenance are significantly reduced, saving much energy up.

4) The distance is longer or about 1000 kilometers between two stations, such as Beijing-Harbin line, Beijing-Shanghai line and other lines, in order to save travelers the time of travelers, suitable locomotive speed is $350 \mathrm{~km} / \mathrm{h}$ speed level of EMU. The speed level of EMU (maximum axle load is about 16 tons) have small impact on the line, The costs of line maintenance are significantly reduced (compared to the locomotive of more than 20 tons axle load), considering from the concept of green, do more contribution to society.

5) The basic resistance of the train will determine the energy consumption of the vehicle, so the following train design process need to consider the aerodynamic focusing problems and then lower the minimum basic resistance, to achieve the purpose of reducing energy consumption.

\section{Concluding remarks}

Based on the description and analysis of main parameters of home and abroad EMU, focused on the domestic Harmony EMU in the condition of different operating mileage and different speed, compared and analyzed their energy consumption, the paper made the most optimal matching in four areas (operation mileage, hours of operation, operating speed and energy consumption), provide a basis to achieve high speed, economy, saving energy and safety of high-speed railway passenger transport.

\section{References}

[1] Zhang Jun,Yang Zichen. Study On Data Fusion of Multi-sensor Data Acquisition System [J].WTransducer and Microsystem Technologies,2014 33(3):52-54.

[2] Miao Jingli, Guo Xiaoming. Research on Vector Control of Induction Motor Based on Grey Sliding Mode[J].Automation \& Instrumentation, 2015 12(1):39-42.

[3] Yue Yunlong,Zuo Xin. Improving Measurement Reliability with Biased Estimation 
forMulti-sensor Data Fusion[J]. Acta Automatica Sinica, 2014 11(09):1843-1852.

[4] Liu Bo,Simulation Research and Implementation of Space Vector Pulse Width Modulation [J]. Electric Machines \& Control Application,2005 11(03):43-52.

[5] Fang Jidong, Application Status and Control Technology of Motor Used in Vehicle[J]. Electrical Machinery Technology,2009 12(3):22-25. 